\title{
Transcultural adaptation and psychometric study of the French version of the nursing home survey on patient safety culture questionnaire
}

Delphine Teigné ${ }^{1,2}$, Guillaume Mabileau' ${ }^{1}$ Emmanuelle Anthoine ${ }^{2,3}$, Marion Lucas ${ }^{1,2}$, Brice Leclère ${ }^{2}$, Leila Moret $^{1,2,3}$ and Noémie Terrien ${ }^{1 *}$

\begin{abstract}
Background: The Nursing Home Survey on Patient Safety Culture (NHSOPS) questionnaire was developed by the Agency for Healthcare Research and Quality (AHRQ), particularly as an intervention to raise staff awareness about patient safety issues. The main objective of the present study was to provide a validated French-language measure of the safety culture (SC) in nursing homes. Thus the aim was i) to carry out a transcultural adaptation into French of the NHSOPS questionnaire, ii) to assess its psychometric properties in a sample of professionals working in French EHPAD facilities and iii) to develop our own tool.

Methods: The study was carried out on volunteering professionals from 61 nursing homes (from January to March 2016). Two phases were conducted: an initial phase involving the translation and cultural adaptation of the questionnaire, and a second phase in which the psychometric properties of the questionnaire were assessed. A Structural Equation Model (SEM) with a maximum likelihood estimation method was used to evaluate the construct validity of the questionnaire. As the fit of the structure was not sufficient, an exploratory factor analysis using a principal axis factoring with an oblique rotation was then performed. Internal consistency was evaluated and we examined test-retest reliability using Intra-class Correlation Coefficients (ICC).

Results: During the initial phase, all items were retained and minor adjustments were made. The participation rate by professionals was $58.4 \%$. The exploratory analysis led to the identification of seven dimensions: Teamwork, Staffing, Compliance with procedures, Handoffs, Feedback and communication about incidents, Supervisor expectations and actions promoting resident safety, Overall perceptions of resident safety and Organizational learning. The SEM confirmed the existence of the seven latent dimensions ( $C F I=0.946 ; T L I=0.933 ;$ SRMR $=0.059 ;$ RMSEA $=0.061$ ); internal consistency was acceptable. ICC per item ranged from 0.19 to 0.88 .

Conclusions: The results from this study were robust on seven dimensions. This French version is the first on Patient SC to have been applied to the medical-social sector caring for dependent elderly people in France. The NHSOPS questionnaire provides the opportunity to broach this subject. A national evaluation campaign should provide the opportunity to confirm or improve this measure.
\end{abstract}

Trial registration: NCT02908373 (September 21, 2016) «Retrospectively registered».

Keywords: Nursing homes, Safety culture, Psychometrics, Survey, Risk management

\footnotetext{
*Correspondence: nterrien@qualirelsante.com

'QualiREL Santé, Hôpital Saint Jacques, 85 rue Saint Jacques, 44093 Nantes,

France

Full list of author information is available at the end of the article
}

(c) The Author(s). 2019 Open Access This article is distributed under the terms of the Creative Commons Attribution 4.0 International License (http://creativecommons.org/licenses/by/4.0/), which permits unrestricted use, distribution, and reproduction in any medium, provided you give appropriate credit to the original author(s) and the source, provide a link to the Creative Commons license, and indicate if changes were made. The Creative Commons Public Domain Dedication waiver (http://creativecommons.org/publicdomain/zero/1.0/) applies to the data made available in this article, unless otherwise stated. 


\section{Background}

In France, the number of dependent elderly people requiring daily care has been constantly on the rise in the last few decades [1]. As a consequence, accommodation for these people has seen many changes, particularly with the creation in France of accredited nursing homes for dependent elderly people (known as Etablissements d'Hébergement pour Personnes Agées Dépendantes - EHPAD). EHPADs are nursing homes that accommodate elderly people who are losing or have lost their physical and/or mental autonomy and cannot stay in their own homes [2]. These facilities provide assistance in daily living (getting up, going to bed, personal hygiene, meals etc) and services such as catering, laundry, and recreational activities. To complete this, medical and paramedical services are delivered by EHPAD salaried professionals (nurses and nursing assistants) and by professionals in private practice attached to the EHPAD (GP, physiotherapist, chiropodist etc). In France, over 585, 000 elderly people were living in nursing homes in 2005 [3]. In a nursing home the living environment, where the concepts of home and institution are juxtaposed, is very different from the hospital care environment. Therefore any reflection needs to be adapted to the constraints and specificities of these nursing homes.

In France, as in other countries, care safety has been a public health concern for many decades in health facilities. It has arrived more recently in nursing homes. Improvement initiatives for care quality and safety in healthcare facilities generally integrate the promotion of the patient safety culture among professionals [4]. Although the efficacy of promotion of this sort in improving patient safety has rarely been studied [5-7], it is nevertheless a lever for the improvement of patient safety. It is supported by the 2012-2017 French national programme on the safety of healthcare. An assessment of healthcare teams' safety culture enables scope for improvements to be identified [8], and, according to Shortell et al., it is one of the 4 main dimensions needed to reach objectives in terms of quality and risk management in healthcare facilities [9].

The safety culture (SC) in healthcare is a multidimensional concept for which there is no consensus definition, whether on the number, the nature or the definition of its different dimensions [10]. The European Society for Quality of Health Care defines SC as a coherent and integrated system of individual and organisational behaviours, based on shared beliefs and values, continuously striving to reduce damage caused to patients potentially linked to patient care procedures [11].

Among the existing questionnaires, the Hospital Survey on Patient Safety Culture (HSOSC) seems to be one of the most widely used questionnaires to assess the SC in health facilities. It was developed by the Agency for Healthcare Research and Quality (AHRQ) in 2004 [12] and has been translated and transculturally adapted many times throughout the world [13-16] as well as in France [17].

Several studies have shown the limitations of the HSOSC questionnaire in the context of nursing homes $[18,19]$. This is why the AHRQ developed a similar questionnaire, adapted however to the specificities of nursing homes, namely the Nursing Home Survey on Patient Safety Culture (NHSOPS) questionnaire [20] which derives scores for 12 dimensions of SC.

This questionnaire is available in (Additional file 1). According to the AHRQ, the NHSOPS questionnaire can be used "as a diagnostic tool to assess the status of patient $\mathrm{SC}$ in a nursing home, as an intervention to raise staff awareness about patient safety issues, as a mechanism to evaluate the impact of patient safety culture improvement initiatives, and as a way to track changes in patient SC over time." [21]. As in the original US version [21], to calculate subscale scores, the average percentage of positive responses on all items in each dimension is calculated. Dimensions are said to be "underdeveloped" if the score is $<50 \%$; "developed" if the score is $>75 \%$ and "developing" if the score is between 50 and 75\% [21].

Many countries (Switzerland, Spain, Norway, Belgium, Germany and China) have translated, adapted and experimented on this questionnaire in the setting of their nursing homes [22-27]. The study of its psychometric properties has already been the basis of two European publications [25, 26], and one Asian publication [27].

The psychometric properties of the Swiss version of the NHSOPS scale were tested. Results of the factorial validity analysis showed nine dimensions, in contrast to 12 dimensions in the original NHSPSC scale [25]. According to these authors, the Swiss version needs further refinement and testing before its use can be recommended in Swiss nursing homes. The Norwegian version of the NHSOPS is fairly close to the Swiss version. The dimension analysis indicated that a modified tendimension model fitted the data-set in a Norwegian community healthcare context with acceptable goodness-of-fit values [24]. Moderate-to-strong correlations were found across the ten latent dimensions. The authors considered that this measure could be recommended as a useful tool to assess staff perceptions of patient safety issues in Norwegian nursing homes. Finally, a four-dimension structure was suggested after completing a principal axis dimension analysis for the Chinese version [27]. The researchers suggested caution in interpreting these findings, and considered that the stability of these item compositions should be tested in different Chinese populations in future studies.

The main objective of this study was to provide a validated tool in French language to measure the safety 
culture (SC) in nursing homes (EHPAD) Thus the aim was i) to perform a transcultural adaptation into French of the NHSOPS questionnaire, ii) to assess its psychometric properties in a sample of professionals in French EHPAD facilities, and iii) if it proved necessary to develop our own measure.

These reflections are part of a French research project on care system performances, called EPHAGE, coordinated by QualiREL Santé and funded by the Direction Général de l'Offre des Soins (DGOS) over the 20152017 period [28].

\section{Methods}

\section{Questionnaire and variables}

The NHSOPS is a self-administered questionnaire intended for all professionals working in EHPAD establishments. It comprises 42 items across 12 dimensions of the safety culture (Table 1 ), and comes under 4 headings: "work in your facility", "communication", "your hierarchy" and "your facility" (Table 1). The 42 items are scored on a 5-point Likert scale: (never, rarely, sometimes, most of the time, always, or do not agree at all, do not agree, agree up to a point, agree, agree completely). "Does not apply or don't know" is included as a response category. Finally, the questionnaire includes items relating to sociodemographic characteristics of the professionals.

\section{Study design}

The adaptation and validation of the NHSOPS were conducted in a descriptive cross-sectional study. This was carried out in two phases: an initial phase in which the translation and cultural adaptation of the questionnaire was conducted and a second phase in which the psychometric validity was assessed.

Table 1 The original patient safety culture dimensions of the NHSOPS used in the French nursing home study

\begin{tabular}{ll}
\hline Dimensions $(n=12)$ & Items \\
\hline Teamwork & 4 \\
Staffing & 4 \\
Compliance with procedures & 3 \\
Training and skills & 3 \\
Non punitive response to mistakes & 4 \\
Handoffs (transfer of information) & 4 \\
Feedback and communication about incidents & 4 \\
Communication openness & 3 \\
Supervisor expectations and actions promoting resident safety & 3 \\
Overall perceptions of resident safety & 3 \\
Management support for resident safety & 3 \\
Organizational learning & 4 \\
\hline
\end{tabular}

\section{Phase 1: translation and transcultural adaptation}

According to guidelines for a transcultural adaptation [29], the NHSOPS questionnaire was translated into French by two native French speakers with fluent English. One of the translators was acquainted with the concepts under assessment; the other translator was naive to the world of healthcare. Any divergence that stemmed from the translations was discussed by the project coordination team in presence of both translators. A first version of the questionnaire in French language was obtained. This first version was back-translated into English by two other bilingual translators whose mother tongue was English. They had previously neither taken part in the first translation work nor had any knowledge of the initial questionnaire. A meeting took place to harmonise the translations thus obtained with the 4 translators and the project coordination team, which yielded a second version of the questionnaire in September 2015.

The second version was tested to make sure that professionals understood the items and that the items were suited to the nursing home sector. Sixteen professionals (GPs, nurses, nursing assistants, catering staff, administrative staff, management) from 4 nursing homes were invited to fill in the questionnaire. They then were asked to evaluate it on the following criteria on an assessment grid: time taken to fill in the questionnaire, clarity of the documents, comprehension of the items and their appropriateness. These evaluations enabled a final version of the questionnaire to be reached.

\section{Phase 2: psychometric validation of the French version of the NHSOPS}

Data collection and data management

The final version was used in a multi-centre study. The survey was carried out from January to March 2016 in 61 nursing homes volunteering to participate and different from those that had tested the questionnaire in Phase 1.

All salaried professionals working in the nursing homes, not only those directly involved in resident care, were invited to participate by a reference person in each facility. The reference person was a professional chosen by the management, and was in charge of the deployment of the process. Private practice professionals involved with the EHPADs were also included in the survey if their involvement in a nursing home was at least $10 \%$ of their working time. Indeed, the AHRQ recommends including private practice professionals in the survey even if they spend only a few hours a week in the nursing home [21]. The level of $10 \%$ of working time amounts to a half day of work in the week. This working time enables professionals to integrate into the organisation of the EHPAD and to interact with permanent salaried professionals, and thus to be sufficiently 
acquainted with the nursing home to respond to the survey.

The survey was conducted in four steps over a sixweek period, as recommended in the AHRQ survey user's guide [21]: 1) publicity and promotion of the survey; 2) questionnaire distribution; 3) issue of reminders; and 4) data collection closure.

All professionals received a questionnaire accompanied by a cover letter in which the purpose of the study was explained. They were asked to return the questionnaire anonymously to a drop-box in the facility. The responses to questionnaires were captured by an outside technician. The data capture was blind and in duplicate, with cross-checking. On reception in the database, the project coordination team members performed random checks of the data capture. Consistency between responses to the questionnaire by the professionals and the responses as captured in the database was checked on 40 questionnaires.

\section{Data analysis}

The rate of participation by professionals were calculated in accordance with recommendations [21] according to the following calculation:

participation rate $=\frac{\text { Number of surveys returned }- \text { incomplete }}{\text { Number of surveys distributed }- \text { ineligible }}$

The "number of surveys distributed" takes account of the surveys handed out by the reference person in the EHPAD; the "number of surveys returned" is the number of surveys posted into the drop-box; "incomplete surveys" are surveys that are returned in which no item is completed; respondents are considered to be "ineligible" when they were survey addressees but were not able to return the questionnaire in the time allowed (sick leaven end of contract, leave etc).

The statistical analyses used the usual techniques for descriptive statistics (frequency, means $\pm \mathrm{SD}$ ). The psychometric analyses were performed in several steps: the first step was to run a Structural Equation Model (SEM) using the maximum likelihood estimation method in order to confirm the structure of the questionnaire in 12 dimensions. This is a comprehensive statistical approach to test hypotheses about relationships among observed variables (i.e. items) and latent variables (i.e. dimensions) [30]. Four statistical indices were considered in order to verify model fit and to select the best-suited model: Steiger's Root Mean Square Error of Approximation (RMSEA) and the Standardized Root Mean Square Residual (SRMR), with the fit considered as good when $<0.1$, and very good when $<0.05$; the Tucker Lewis Index (TLI) and the Comparative Fit Index (CFI) were considered as acceptable fit when $>0.9$
[31]. Parameter estimations used the linear structural relationship approach developed by Jöreskog [32].

As these analyses revealed that the fit of the structure was not sufficient, an exploratory factor analysis (EFA) was then performed in order to identify the latent relational structure among items, leading to the identification of the new dimensions. Items with a percentage of non-available values (missing values and "Not Applicable" answers) of over $20 \%$, or with a floor/ceiling effect over $50 \%$, were eliminated. Missing data were not imputed, as they were missing at random. If two items exhibited a Spearman's correlation coefficient over 0.8, only the more relevant of the two was kept (expert discussion). With the remaining items, the underlying dimensions were identified using a principal axis factoring on two thirds of the data randomly split, with a parallel analysis to determine the number of factors to retain [33]. This was also supported by the KaiserMeyer-Olkin (KMO) statistic for sampling adequacy, and the Bartlett's test of sphericity. For an item to be attributed to a factor, the corresponding factor loading was to exceed 0.40 . Eigenvalues and percentage of variance were also considered. An oblique rotation (oblimin) was used, as the factors identified were not totally uncorrelated (Additional file 2).

A final SEM was performed to examine the structure validity of the refined questionnaire on the remaining third of the data. The model hypothesized from the exploratory analysis was tested to confirm how well the data fitted the postulated structure.

Cronbach's $\alpha$-coefficients were computed to evaluate internal consistency [34]. Homogeneity was interpreted as acceptable if the alpha value was greater than 0.70 [35].

Finally, to evaluate reproducibility, a test-retest procedure was conducted in 5 nursing homes. Thirty-five professionals were asked to answer the questionnaire twice with a 2-week interval between test and retest. Intra-class Correlation Coefficients (ICC) were computed and considered satisfactory if greater than 0.60 [36].

All the study analyses were computed using $\mathrm{R}$ package version 3.4.3.

\section{Ethical and consent considerations}

Participation was voluntary, and completion of the questionnaire was considered as informed consent. According to articles L1121-1 and R1121-2 in the French code of Public Health, Institutional Review Board (IRB) approval was not necessary.

\section{Results}

Translation and transcultural adaptation (phase 1)

All items were retained. Minor adjustments were made in the course of reconciliation meetings. They concerned choices of wording not affecting the patient safety 
subject matter and not specific to nursing home settings. For instance "this facility attaches importance to sharing the ideas and suggestions of staff members" versus "staff ideas and suggestions are valued in this nursing home" (item B7), or " the management often goes round the home to assess the care given to the residents" versus "management often walks around the nursing home to check on resident care" (item D9).

All the professionals $(n=16)$ that were asked to make sure the items were comprehensible responded. Three quarters of the testing professionals responded positively to the statement: "I have all the necessary information to respond to the questionnaire". The questions were clear for $93.8 \%$ of the respondents and $87.6 \%$ found the questionnaire easy to fill in. Completion of the questionnaire was timed at $16 \mathrm{~min}$. The length of the questionnaire was underlined by only two participants. The 42 items were retained. One item was rephrased on the basis of professionals' remarks (item A17). The final French version of the questionnaire is provided in (Additional file 1).

\section{Samples characteristics (Table 2)}

The administration of the questionnaire targeted 3,538 professionals. There were 84 "ineligible" professionals. The number of professionals who responded was 2,036. There were 16 incomplete questionnaires. The completion rate for the 2020 questionnaires was $99.04 \%$, and the final participation rate was $58.4 \%$.

Almost half of the respondents (41.6\%) belonged to the paramedical field. The age of the professionals was $>35$ for $56.6 \%$. Half the respondents had worked in the profession for under 10 years (50.4\%). Weekly working hours were 25 to $35 \mathrm{~h}$ for the majority (Table 2). $82.1 \%$ of the respondents were working in contact with the residents.

\section{Psychometric validation analysis of the French version of the NHSOPS (Phase 2) \\ First step: test of the original structure}

The SEM fit indices were not acceptable $(\mathrm{CFI}=0.89$; TLI $=0.88 ; \quad$ SRMR $=0.06 ; \quad$ RMSEA $=0.05 \quad$ (outputs Additional file 3).

\section{Second step: refinement of the original structure}

Among the 42 items, 2 were removed because of their missing value rate $>20 \%$ (A10 and A17) and one because of ceiling effect (C3).

No pairs of items had Spearman's correlation coefficients exceeding 0.8 (Additional file 4).

The parallel analysis suggested that seven factors should be retained in the factor analysis (Additional file 5), accounting for $57.1 \%$ of the variance after oblique rotation (Table 3). After selecting items with
Table 2 Respondent characteristics for the survey $(n=2020)$

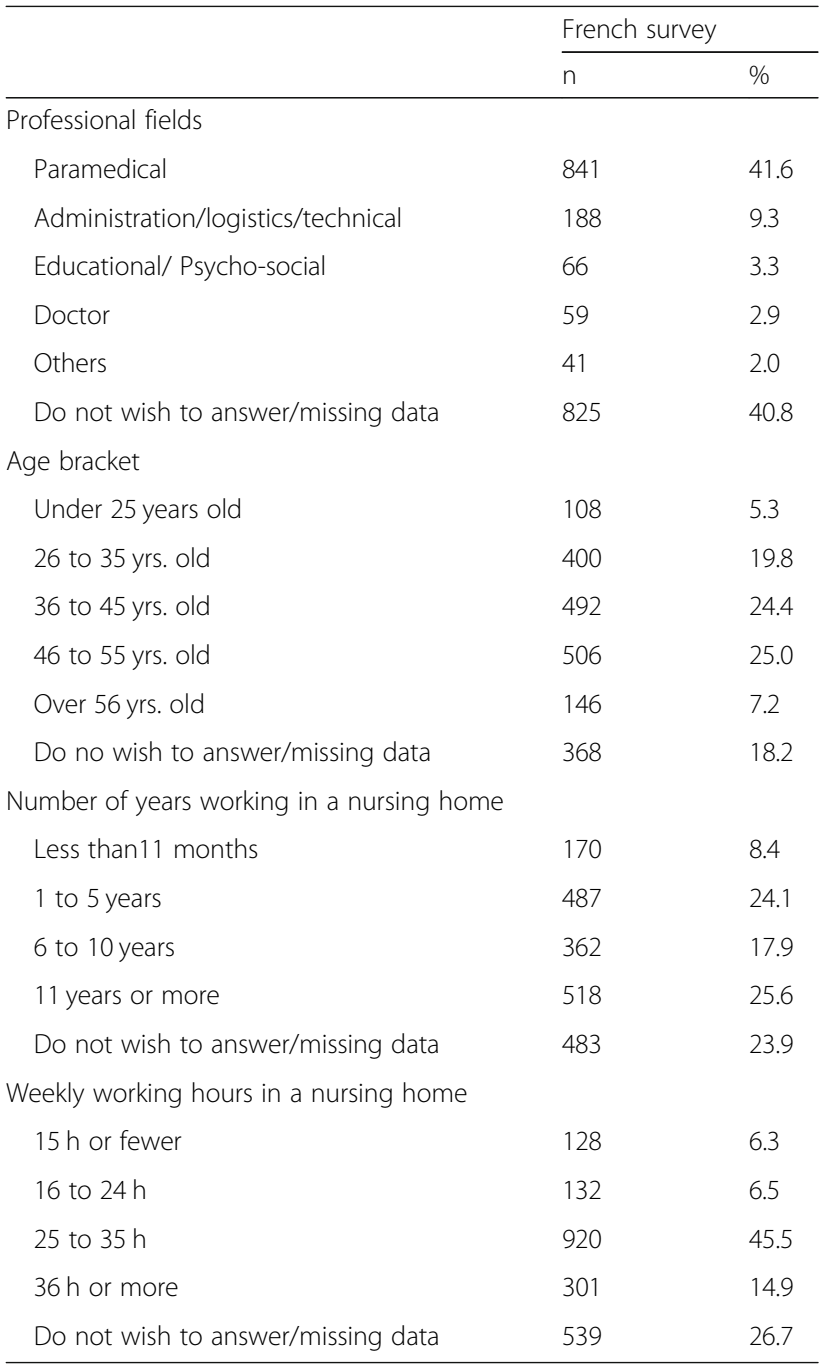

factor loadings exceeding 0.4, the seven factors identified were composed of 22 items. The correlation coefficients between these factors ranged from 0.13 to 0.58 (Additional file 2). The KMO statistic for factor fit was calculated at 0.91, and Bartlett's test of sphericity was significant $(p<0.001)$.

The NHSOPS-F was thus composed of 22 items and seven factors, which correspond, in part, to dimensions in the NHSOPS: Teamwork (A1, A2, A5, A9), Staffing (A3, A8), Compliance with procedures (A6, A14), Handoffs (B1, B2, B3, B10), Feedback and communication about incidents (B5, B6, B8), Supervisor expectations and actions promoting resident safety $(\mathrm{C} 1, \mathrm{C} 2)$, and Overall perceptions of resident safety and organizational learning (D4, D5, D6, D8, D10) (Table 3). The description of answers according to response choices are presented in (Additional file 6).

The SEM on the remaining third of the data confirmed the existence of the seven latent factors. All the 
Table 3 Results of the Principal Axis factoring (PAF)

\begin{tabular}{|c|c|c|c|c|c|c|c|}
\hline & Factor 1 & Factor 2 & Factor 3 & Factor 4 & Factor 5 & Factor 6 & Factor 7 \\
\hline \multicolumn{8}{|l|}{ Factor loadings } \\
\hline A1 & 0.01 & -0.01 & 0.8 & 0.05 & 0.03 & 0.00 & -0.04 \\
\hline$A 2$ & 0.03 & -0.01 & 0.86 & -0.02 & -0.02 & -0.01 & -0.01 \\
\hline A3 & 0.09 & 0.01 & 0.03 & -0.05 & -0.09 & 0.74 & 0.04 \\
\hline A5 & -0.04 & 0.09 & 0.57 & 0.02 & 0.02 & 0.04 & 0.11 \\
\hline A6 & 0.01 & 0.05 & 0.02 & 0.00 & 0.73 & 0.06 & -0.05 \\
\hline A8 & -0.07 & 0.00 & -0.02 & 0.06 & 0.12 & 0.74 & -0.03 \\
\hline A9 & -0.1 & 0.05 & 0.51 & 0.05 & 0.07 & 0.00 & 0.13 \\
\hline A14 & 0.04 & -0.02 & 0.01 & 0.01 & 0.72 & -0.03 & 0.08 \\
\hline B1 & 0.04 & 0.75 & 0.06 & -0.05 & -0.03 & 0.03 & -0.03 \\
\hline B2 & 0.01 & 0.75 & 0.05 & 0.01 & 0.01 & -0.01 & -0.02 \\
\hline B3 & -0.07 & 0.67 & -0.09 & 0.04 & 0.01 & 0.04 & 0.05 \\
\hline B5 & 0.03 & 0.04 & 0.02 & 0.06 & 0.00 & 0.04 & 0.67 \\
\hline B6 & -0.03 & 0.07 & 0.07 & -0.09 & 0.12 & -0.06 & 0.55 \\
\hline B8 & 0.26 & 0.00 & 0.02 & 0.17 & -0.02 & 0.04 & 0.47 \\
\hline B10 & 0.09 & 0.62 & -0.02 & 0.05 & 0.06 & -0.06 & 0.09 \\
\hline $\mathrm{C} 1$ & 0.02 & 0.04 & 0.04 & 0.71 & -0.01 & 0.03 & 0.08 \\
\hline$C 2$ & 0.01 & -0.01 & 0.03 & 0.79 & 0.01 & -0.02 & -0.03 \\
\hline D4 & 0.55 & 0.11 & 0.05 & 0.11 & -0.03 & 0.01 & 0.02 \\
\hline D5 & 0.79 & 0.05 & -0.04 & 0.09 & 0.01 & 0.01 & 0.01 \\
\hline D6 & 0.88 & 0.00 & 0.03 & -0.03 & -0.02 & 0.02 & 0.02 \\
\hline D8 & 0.67 & -0.04 & 0.04 & -0.06 & 0.15 & 0.00 & 0.01 \\
\hline D10 & 0.40 & 0.16 & -0.1 & 0.17 & 0.09 & 0.03 & 0.07 \\
\hline \multicolumn{8}{|l|}{ Eigenvalues } \\
\hline & 7.20 & 1.66 & 1.09 & 0.94 & 0.78 & 0.55 & 0.36 \\
\hline \multicolumn{8}{|c|}{ Percentage of variance accounted for } \\
\hline$\%$ & 32.7 & 7.5 & 4.9 & 4.3 & 3.5 & 2.5 & 1.6 \\
\hline Cumulative \% & 32.7 & 40.3 & 45.2 & 49.5 & 53 & 55.5 & 57.1 \\
\hline
\end{tabular}

Table 4 Cronbach's a-coefficients for the seven dimensions retained

\begin{tabular}{|c|c|}
\hline $\begin{array}{l}\text { Dimensions ( } n=7 \text { ) } \\
\text { (corresponding factors) }\end{array}$ & $\begin{array}{l}\text { Cronbach's } \\
\text { a-coefficients }\end{array}$ \\
\hline $\begin{array}{l}\text { Overall perceptions of resident safety and } \\
\text { Organizational learning (factor 1) }\end{array}$ & 0.865 \\
\hline Handoffs (transfer of information) (factor 2) & 0.824 \\
\hline Teamwork (factor 3) & 0.832 \\
\hline $\begin{array}{l}\text { Supervisor expectations and actions promoting } \\
\text { resident safety (factor 4) }\end{array}$ & 0.745 \\
\hline $\begin{array}{l}\text { Compliance with procedures } \\
\text { (factor 5) }\end{array}$ & 0.720 \\
\hline Staffing (factor 6) & 0.738 \\
\hline $\begin{array}{l}\text { Feedback and communication about incidents } \\
\text { (factor } 7 \text { ) }\end{array}$ & 0.727 \\
\hline
\end{tabular}

indices indicated a good fit to the data $(\mathrm{CFI}=0.960$; $\mathrm{TLI}=0.951 ; \quad \mathrm{SRMR}=0.044 ; \quad \mathrm{RMSEA}=0.046)$ and the structural coefficients were highly significant $(P<0.001)$ (Additional files 7 and 8).

Cronbach's $\alpha$-coefficients were $>0.70 \quad$ (Table 4). Twenty-one professionals answered the questionnaire twice. The ICC per item ranged from 0.19 to 0.88 (Table 5).

\section{Discussion}

The psychometric properties of the NHSOPS were reported by the American authors to be satisfactory [21] These authors suggested that the scale could be used internationally, and they produced a document to guide transcultural adaptation procedures and questionnaire administration [20]. These various recommendations were complied with in the present study. 
Table 5 Intra-class correlation (ICC) per item

\begin{tabular}{|c|c|c|}
\hline Dimensions $(n=7)$ & Items & Intra-class correlation \\
\hline \multicolumn{3}{|c|}{ Overall perceptions of resident safety and Organizational learning } \\
\hline & D4 & 0.61 \\
\hline & D5 & 0.76 \\
\hline & D6 & 0.82 \\
\hline & D8 & 0.54 \\
\hline & D10 & 0.37 \\
\hline \multicolumn{3}{|c|}{ Handoffs (transfer of information) } \\
\hline & B1 & 0.82 \\
\hline & B2 & 0.57 \\
\hline & B3 & 0.88 \\
\hline & B10 & 0.60 \\
\hline \multicolumn{3}{|l|}{ Teamwork } \\
\hline & A1 & 0.51 \\
\hline & $\mathrm{A} 2$ & 0.70 \\
\hline & A5 & 0.43 \\
\hline & A9 & 0.52 \\
\hline \multicolumn{3}{|c|}{ Supervisor expectations and actions promoting resident safety } \\
\hline & $\mathrm{C} 1$ & 0.58 \\
\hline & $\mathrm{C} 2$ & 0.45 \\
\hline \multicolumn{3}{|c|}{ Compliance with procedures } \\
\hline & A14 & 0.64 \\
\hline & A6 & 0.65 \\
\hline \multicolumn{3}{|l|}{ Staffing } \\
\hline & $\mathrm{A} 3$ & 0.81 \\
\hline & A8 & 0.86 \\
\hline \multicolumn{3}{|c|}{ Feedback and communication about incidents } \\
\hline & B5 & 0.76 \\
\hline & B6 & 0.59 \\
\hline & B8 & 0.19 \\
\hline
\end{tabular}

The first step consisting in the translation and transcultural adaptation culminated in the elaboration of the French version of the NHSOPS, which maintains the original 42 items. The adaptation of the questionnaire in other countries had produced versions comprising 42 $[25,27]$ or 43 items [24] (one extra item in the "Handoffs" domain).

The second stage of psychometric validation was then conducted, concluding to a seven-factor structure. The factor (dimension) "Teamwork" returns to the 4 original items in this domain and explores support, mutual respect and collaboration among colleagues. The dimension "Staffing" explores staffing numbers in relation to workload ( 2 items maintained from the 4 original items). The dimension "Compliance with procedures" explores general compliance with the mandatory procedures in the facility whatever the functioning difficulties encountered by professionals ( 2 items out of the original 3). The dimension "Handoffs" maintains the 4 initial items, and assesses communication for resident care within the EHPAD and with outside structures. The dimension "Feedback and communication about incidents" explores the way in which potential or actual incidents are dealt with, and the sharing of solutions (3 items out of the initial 4). The dimension "Supervisor expectations and actions promoting resident safety" explores the valorisation of professional compliance with procedures and receptivity by supervisors towards ideas for improvement ( 2 of the 3 original items). The dimension "Overall perceptions of resident safety and Organizational learning" comprises 5 of the original 7 items derived from 2 initial dimensions. This theme explores the ability of the facility to take account of its mistakes and make changes, and the overall quality of care provided for residents.

In our model, the number of items included was 22 . These items initially belonged to 8 dimensions in the original American questionnaire. The factor analysis on the seven factors retained accounted for $57.1 \%$ of the variance.

In studies in other countries, the exploratory factor analyses conducted led to a reduction in the number of dimensions from 12 to 9 for Switzerland [25] and 10 for Norway [24]. The numbers of items retained were respectively 42 and 32 . Explained variance was $58.1 \%$ for the Swiss study, while this result was not presented in the Norwegian study. For China, Lin et al. presented a final model comprising 4 dimensions and 29 items [27]. The explained variance reached $52.8 \%$.

These different studies have produced different models for the NHSOPS. The advantage of our model resides in the fact that i) the number of factors is sufficient to claim precision in the structure of the model, ii) our model was constructed from a fairly large database ( $n=2020$ questionnaires and 61 EHPAD facilities). This database was considerably larger than that found in studies in other countries $(n=466$ questionnaires from 12 establishments in Norway [24], $n=367$ questionnaires and 9 establishments in Switzerland [25] and $n=306$ questionnaires from 30 establishments in China [27]). Our methodology was exactly the same as that used by Lin et al., but their smaller sample size did not enable them to achieve a model as refined as ours. It can also be noted that these studies in different countries targeted certain professional categories (managers [27], only professionals directly involved in care [25]), which, as acknowledged by the authors, was a limitation of their data. It can be recalled that the AHRQ recommends soliciting all professionals in nursing homes to respond to the survey [21]. The sample of professionals in our study was 
for its part representative of the population working in EHPAD facilities in France [37].

Finally, it can be noted that the participation rate among EHPAD professionals in our study was 58.4\%. The rates in the other countries were 66\% [25], 69\% [24], and $100 \%$ [27]. The participation rates are not comparable because of the differences in the professional populations targeted. Because of the mode of administration of the questionnaires, reasons for nonparticipation in our study are not known.

Generally speaking, there is no consensus across countries on the definition of the safety culture (SC) and the dimensions that make it up (in terms of number, content and denomination) [38]. In France, the HAS (French health authority) retains the definition of the European Society for the Quality of Health Care: "a coherent and integrated system of individual and organisational behaviours, based on shared beliefs and values, continuously striving to reduce damage caused to patients potentially linked to patient care procedures" [11]. In France the HAS also recommends the exploration of 10 dimensions of the SC in care provision. They are as follows: teamwork within the department, teamwork between departments, human resources, non punitive response to mistakes, frequency of notification of adverse events, freedom of expression, management support for care safety, expectations and actions by management for care safety, learning and continuous improvement, global perceptions of safety.

If we compare these 10 dimensions generally used in France with the 7 dimensions in our model, six explicitly coincide - teamwork within the department (teamwork), teamwork between departments (handoffs), human resources (staffing), expectation and actions by management for care safety, learning and continuous improvement, global perceptions of safety [11]. One dimension is not explored in our model, since it was not initially included in the AHRQ version of the NHSOPS - the "frequency of notification of adverse events". Finally, three dimensions are not found explicitly, but their general themes are found in items C1, C2, D4, D5 and D10 (item labels provided in Additional file 1). Likewise, "freedom of expression" and "non-punitive response to mistakes" are contained in items B5, B6 and B8.

One limitation of our study is found in our test-retest results. Certain items have a very low ICC. Polit [39] in a recent article highlighted the importance of the sampling procedure in this type of test, and in particular the need for heterogeneity among respondents (there was little heterogeneity in our sample), and the need for a sample of at least 50 (only 21 in our study). Polit also suggests detailed comparison of responses to each item between the two administrations, coupled with in-depth interviews of certain respondents to explore the coherence of responses. The test-retest will be reiterated before the finalisation of the scale (as is indeed suggested by Polit [39]), within a study conducted on an EHPAD sample extended to the national territory as a whole. The checklists for the design of reliability tests will be taken into account [39]. This national study should confirm or improve the structure of our model. The 22 items in the model will be maintained in the NHSOPS-F questionnaire. Professionals will also be invited to respond to extra items (relating to the frequency of notification of adverse events) and to original items maintained for pedagogical purposes at the time of feedback on results to the professionals. It should indeed be remembered that the NHSOPS questionnaire gives professionals the opportunity to exchange views on SC in nursing homes in the setting of the deployment of risk management in healthcare [20].

\section{Conclusion}

The NHSOPS questionnaire, presented here in its French language version, is the first questionnaire on Patient SC that has been applied to the medico-social sector in France. The analysis of its psychometric properties has enabled the validation of seven dimensions. One limitation of our study is found in our test-retest results. This instrument was developed from a large database. An upcoming national survey in the second semester of 2019 should contribute to confirming or improving the structure of our model. In the meantime, the NHSOPS questionnaire gives professionals the opportunity to exchange viewpoints on SC in nursing homes in the context of the deployment of risk management in healthcare. This study is part of a research project [28], the results of which will enable programmes of support and awareness-raising on these $\mathrm{SC}$ issues in nursing homes to be designed. These assessment tools come within the scope of the continuing promotion of healthcare safety endorsed by healthcare policies and supported by recent institutional and regulatory evolutions in the area of healthcare safety.

\section{Additional files}

Additional file 1: a. Nursing Home Survey on Patient Safety. b. French version of the NHSOPS questionnaire. (ZIP $334 \mathrm{~kb}$ )

Additional file 2: Inter-correlations across the 7 final dimensions retained. (PDF $91 \mathrm{~kb}$ )

Additional file 3: Original SEM outputs. (PDF $103 \mathrm{~kb}$ )

Additional file 4: Inter-correlations across the 42 items of the questionnaire. (PDF $186 \mathrm{~kb}$ )

Additional file 5: Parallel analysis scree plots. (PNG $12 \mathrm{~kb}$ )

Additional file 6: Description of item responses per answer choice (percentages). (PDF $171 \mathrm{~kb}$ )

Additional file 7: Structural Equation Model outputs. (PDF 237 kb) Additional file 8: Structural Equation Model diagram. (PNG 28 kb) 


\section{Abbreviations}

AHRQ: Agency for Healthcare Research and Quality; CFI: Comparative Fit Index; DGOS: Direction Général de I'Offre des Soins; EHPAD: Etablissements d'Hébergement pour Personnes Agées Dépendantes; HSOSC: Hospital Survey on Patient Safety Culture; ICC: Intra-class Correlation Coefficients; IRB: Institutional Review Board; NHSOPS: Nursing Home Survey on Patient Safety Culture; RMSEA: Steiger's Root Mean Square Error of Approximation; SC: Safety Culture; SEM: Structural Equation Model; SRMR: Standardized Root Mean Square Residual; TLI: Tucker Lewis Index

\section{Acknowledgements}

The authors would like to thank the DGOS (French general management for care provision). They would also like to thank all 61 nursing homes and their staff who took part in the EPHAGE research project. They would likewise like to thank Dr. J-L Quenon, co-director of the CCECQA (Quality and Assessment coordination team of the Aquitaine region) for proof-reading this article and for his valuable advice.

\section{Authors' contributions}

DT operative project leader, participated in the data collection, in the interpretation of the data and drafted the manuscript. GM performed the statistical analysis, interpreted the data, and helped to draft the manuscript. EA participated in the design of the study and helped to draft the manuscript. ML participated in the data collection and revised manuscript. $B L$ designed the study, participated in the interpretation of the data and revised the manuscript. LM designed the study, participated in the interpretation of the data, and revised manuscript. NT designed the study, was principal investigator, participated in the interpretation of the data and revised the manuscript. All authors have read and approved the final manuscript.

\section{Funding}

These reflections are part of a French research project on care system performances, called EPHAGE, coordinated by QualiREL Santé and funded by the Direction Général de l'Offre des Soins (DGOS) over the 2015-2017 period. DGOS did not participate in the design of the study, in the collection, interpretation, or analysis of the data, nor in the drafting of the manuscript.

\section{Availability of data and materials}

Please contact the corresponding author should you require any of the results from this study.

\section{Ethics approval and consent to participate}

Participation was voluntary, and completion of the questionnaire was considered as informed consent. According to articles L1121-1 and R1121-2 in the French code of public health, non interventional research does not require any IRB approval, which is solely mandatory for interventional research. Relevant authority of French non interventional research is the Cnil (Commission Nationale de l'Informatique et des Libertés). Our research is registered by the Cnil Under ref. 915719 (December 1, 2015).

\section{Consent for publication}

Not applicable

\section{Competing interests}

The authors declare that they have no competing interests.

\section{Author details}

'QualiREL Santé, Hôpital Saint Jacques, 85 rue Saint Jacques, 44093 Nantes, France. ${ }^{2}$ Public Health Department, University Hospital of Nantes, 85 rue Saint-Jacques, 44093 Nantes Cedex 1, France. ${ }^{3}$ UMR INSERM U1246-SPHERE "methodS for Patients-centered outcomes \& HEalth REsearch", University of Nantes, University of Tours, 22 Boulevard Benoni Goullin, 44000 Nantes, France.
Received: 27 September 2018 Accepted: 8 July 2019

Published online: 15 July 2019

\section{References}

1. Weber M, Vérollet Y. Conseil économique social et environnemental. La dépendance des personnes âgées: avis du conseil économique, social et environnemental présenté par Monique Weber et Yves Vérollet, rapporteurs de la commission temporaire. Journaux officiels: Documentation française. Paris; 2011. https://www.ladocumentationfrancaise.fr/var/storage/rapportspublics/114000337.pdf. Accessed 24 Nov 2015.

2. Journal officiel,. LOI n 2002-2 du 2 janvier 2002 rénovant l'action sociale et médico-sociale. https://www.legifrance.gouv.fr/eli/loi/2002/1/2/ MESX0000158L/jo/texte.

3. Muller M. Etudes et Résultats 728000 résidents en établissements d'hébergement pour personnes âgées en 2015. Premiers résultats de l'enquête EHPA 2015. 2017. http://drees.solidarites-sante.gouv.fr/MG/pdf/er1 015.pdf. Accessed 29 Sep 2017.

4. Haute Autorité de Santé. La sécurité des patients. Mettre en oeuvre la gestion des risques associés aux soins en établissement de santé. Des concepts à la pratique. 2012. https://www.has-sante.fr/upload/docs/ application/pdf/2012-04/guide_gdr_pages1a64.pdf. Accessed 24 Oct 2016.

5. Nieva VF. Safety culture assessment: a tool for improving patient safety in healthcare organizations. Qual Saf Health Care. 2003;12:17ii-23.

6. Scott T, Mannion R, Marshall M, Davies H. Does organisational culture influence health care performance? A review of the evidence. J Health Serv Res Policy. 2003:8:105-17.

7. The Health Foundation Inspiring Improvement. Does improving safety culture affect patient outcomes? 2011.

8. Gaba DM, Singer SJ, Rosen AK. Safety culture: is the "unit" the right "unit of analysis"? Crit Care Med. 2007;35:314-6.

9. Shortell S, Gillies R, Anderson D, Erikson K, Mitchell J. Remaking health care in America. Hosp Health Netw. 1996;6:43-4.

10. Guldenmund FW. The nature of safety culture: a review of theory and research. Saf Sci. 2000;34:215-57.

11. Kristensen $S$, Bartels P. Use of patient safety culture instruments and recommendations. Aarhus, Denmark, European Society for Quality in HealthCare - Office for Quality Indicators. 2010.

12. Agency for Healthcare Research and Quality. Hospital Survey On Patient Safety Culture. 2014. https:/www.ahrq.gov/sites/default/files/wysiwyg/ professionals/quality-patient-safety/patientsafetyculture/hospital/resources/ hospscanform.pdf. Accessed 18 Aug 2016.

13. Hammer A, Ernstmann N, Ommen O, Wirtz M, Manser T, Pfeiffer Y, et al. Psychometric properties of the hospital survey on patient safety culture for hospital management (HSOPS_M). BMC Health Serv Res. 2011;11. https:// doi.org/10.1186/1472-6963-11-165.

14. Stoyanova R, Dimova R, Tarnovska M, Boeva T. Linguistic validation and cultural adaptation of Bulgarian version of hospital survey on patient safety culture (HSOPSC). Open Access Maced J Med Sci. 2018;6. https://doi.org/1 0.3889/oamjms.2018.222.

15. Tereanu C, Alan SMITHS, Ghelase MS, Sampietro G, Molnar A, Moraru D, et al. Psychometric properties of the Romanian version of the hospital survey on patient safety culture (HSOPS). MAEDICA - J Clin Med. 2018;13:34-43.

16. de Andrade LEL, de Melo LOM, da Silva IG, de Souza RM, de Lima ALB, de Freitas MR, et al. Adaptação e validação do Hospital Survey on Patient Safety Culture em versão brasileira eletrônica. Epidemiol E Serviços Saúde. 2017:26:455-68

17. Occelli P, Quenon J-L, Kret M, Domecq S, Delaperche F, Claverie O, et al. Validation of the French version of the hospital survey on patient safety culture questionnaire. Int J Qual Health Care. 2013;25:459-68.

18. Bonner AF, Castle NG, Perera S, Handler SM. Patient safety culture: a review of the nursing home literature and recommendations for practice. Ann Long-Term Care Off J Am Med Dir Assoc. 2008;16:18.

19. Castle NG, Wagner LM, Perera S, Ferguson JC, Handler SM. Assessing resident safety culture in nursing homes: using the nursing home survey on resident safety. J Patient Saf. 2010;6:59-67.

20. Agency for Healthcare Research and Quality. Items ans dimensions: nursing Home Survey on Patient Safety Culture. 2008. https://www.ahrq.gov/sites/ default/files/wysiwyg/professionals/quality-patient-safety/ patientsafetyculture/nursing-home/nhguide/sops-nursing-home-items.pdf. Accessed 18 Aug 2016. 
21. Westat R, Sorra J, Franklin M, Streagle S. Survey User's guide nursing home survey on patient safety culture. 2008. https://www.ahrq.gov/sites/default/ files/publications/files/nhguide.pdf. Accessed 31 Mar 2017.

22. Desmedt $M$, Petrovic $M$, Beuckelaere $P$, Vandijck $D$. Assessing resident safety culture in six nursing homes in Belgium. J Patient Saf. 2018.

23. Machón M, Vergara I, Silvestre C, Pérez P, Alías G, Vrotsou K. Adaptación transcultural al castellano del cuestionario Nursing Home Survey on Patient Safety Culture. Rev Calid Asist. 2014;29:99-103.

24. Cappelen K, Aase K, Storm M, Hetland J, Harris A. Psychometric properties of the nursing home survey on patient safety culture in Norwegian nursing homes. BMC Health Serv Res. 2016;16. https:/doi.org/10.1186/s12913-016-1706-x.

25. Zúñiga F, Schwappach D, De Geest S, Schwendimann R. Psychometric properties of the Swiss version of the nursing home survey on patient safety culture. Saf Sci. 2013;55:88-118.

26. Thürmann P. Arzneimitteltherapiesicherheit in Alten-und Pflegeheimen: Querschnittsanalyse und Machbarkeit eines multidisziplinären Ansatzes. 2009. https://www.bundesgesundheitsministerium.de/fileadmin/Dateien/5 Publikationen/Gesundheit/Berichte/Abschlussbericht_Arzneimitteltherap iesicherheit_in_Alten-_und_Pflegeheimen_Querschnittsanalyse_und_ Machbarkeit_eines_multidisziplinaeren_Ansatzes.pdf. Accessed 1 Mar 2017.

27. Lin S-Y, Tseng WT, Hsu M-J, Chiang H-Y, Tseng H-C. A psychometric evaluation of the Chinese version of the nursing home survey on patient safety culture. J Clin Nurs. 2017;26:4664-74.

28. Terrien $\mathrm{N}$, Moret $\mathrm{L}$, Leclere $\mathrm{B}$. Measuring impact on safety culture in nursing homes, a multifaceted device for the analysis of care associated adverse events. 2015. https://clinicaltrials.gov/ct2/show/study/NCT029083 73?term=ehpage\&rank=1. Accessed 23 Sept 2016.

29. Beaton DE, Bombardier C, Guillemin F, Ferraz MB. Guidelines for the process of cross-cultural adaptation of self-report measures. Spine. 2000;25:3186-91.

30. Hoyle R. Structural equation modeling: concepts, issues and applications. SAGE; 1995.

31. Anderson JC, Gerbing DW. The effect of sampling error on convergence, improper solutions, and goodness-of-fit indices for maximum likelihood confirmatory factor analysis. Psychometrika. 1984;49:155-73.

32. JöReskog KG. A general method for analysis of covariance structures. Biometrika. 1970;57:239-51.

33. Gaskin CJ, Happell B. On exploratory factor analysis: A review of recent evidence, an assessment of current practice, and recommendations for future use. International Journal of Nursing Studies. 2014;51:511-21.

34. Cronbach LJ. Coefficient alpha and the internal structure of tests. psychometrika. 1951;16:297-334.

35. Streiner D, Geoffrey R. Health measurement scale: a practical guide to their development and use. 3rd ed. Oxford: Oxford University Press; 2003.

36. Fermanian J. Measuring agreement between 2 observers: a quantitative case (in French). Rev Epidemiol Sante Publique. 1984;6:408-13.

37. Perrin-Haynes J. Document de travail: Les établissements d'hébergement pour personnes âgées Activité, personnel et clientèle au 31 décembre 2007. 2010. http://drees.social-sante.gouv.fr/IMG/pdf/seriestat142-2.pdf.

38. Haute Autorité de Santé. La culture de sécurité des soins : du concept à la pratique. 2010. https:/wwww.has-sante.fr/upload/docs/application/pdf/2011-02/ culture_de_securite_des_soins_du_concept_a_la_pratique.pdf.

39. Polit D. Getting serious about test-retest reliability: a critique of retest research and some recommendations. Qual Life Res. 2014;23:1713-20.

\section{Publisher's Note}

Springer Nature remains neutral with regard to jurisdictional claims in published maps and institutional affiliations.

Ready to submit your research? Choose BMC and benefit from:
- fast, convenient online submission
- thorough peer review by experienced researchers in your field
- rapid publication on acceptance
- support for research data, including large and complex data types
- gold Open Access which fosters wider collaboration and increased citations
- maximum visibility for your research: over 100M website views per year
At BMC, research is always in progress.
Learn more biomedcentral.com/submissions

